\title{
Challenges and Strategies in Thermal Processing of Amorphous Solid Dispersions: A Review
}

\author{
Justin S. LaFountaine, ${ }^{1,2}$ James W. McGinity, ${ }^{1}$ and Robert O. Williams III ${ }^{1}$
}

Received 17 June 2015; accepted 8 August 2015; published online 26 August 2015

\begin{abstract}
Thermal processing of amorphous solid dispersions continues to gain interest in the pharmaceutical industry, as evident by several recently approved commercial products. Still, a number of pharmaceutical polymer carriers exhibit thermal or viscoelastic limitations in thermal processing, especially at smaller scales. Additionally, active pharmaceutical ingredients with high melting points and/or that are thermally labile present their own specific challenges. This review will outline a number of formulation and process-driven strategies to enable thermal processing of challenging compositions. These include the use of traditional plasticizers and surfactants, temporary plasticizers utilizing sub- or supercritical carbon dioxide, designer polymers tailored for hot-melt extrusion processing, and KinetiSol ${ }^{\circledR}$ Dispersing technology. Recent case studies of each strategy will be described along with potential benefits and limitations.
\end{abstract}

KEYWORDS: amorphous solid dispersions; hot-melt extrusion; KinetiSol ${ }^{\circledR}$ Dispersing; plasticizers; polymers; supercritical carbon dioxide.

\section{INTRODUCTION}

Drugs with poor aqueous solubility continue to represent a significant challenge for oral delivery, as dissolution in the gastrointestinal tract is a prerequisite to absorption. It has been reported that up to $70 \%$ of investigational new drugs (1) and up to $40 \%$ of marketed drugs (2) exhibit poor aqueous solubility and fall into class II or IV of the Biopharmaceutics Classification System (3). A number of solubility-enhancing strategies have been investigated over the last few decades to enable oral delivery of these drugs $(4,5)$. Examples include the use of salts or cocrystals (6), lipid vehicles (7), cyclodextrins (8), micronization and nanoparticle engineering $(9,10)$, and amorphous solid dispersions (11-13).

Amorphous solid dispersions (ASDs) in particular have attracted increased attention and commercial success in the pharmaceutical industry over the last two decades (14). Some notable examples include Kaletra ${ }^{\circledR}$, Onmel®, Incivek ${ }^{\circledR}$, Zelboraf®, Kalydeco $\AA$, and Noxafil $\AA$, among others $(1,15)$. There are a number of reasons why ASDs are becoming the preferred technology to enable the delivery of poorly watersoluble drugs. First, dissolution of amorphous drug can result in an apparent solubility that is orders of magnitude higher than the thermodynamic solubility of the crystalline

\footnotetext{
${ }^{1}$ Division of Pharmaceutics, College of Pharmacy, The University of Texas at Austin, 2409 University Avenue, Campus Mail Code A1902, Austin, Texas 78712, USA.

${ }^{2}$ To whom correspondence should be addressed. (e-mail: justin.lafountaine@utexas.edu)
}

counterpart (16). This increase in apparent solubility in ASDs, along with other supersaturating systems, does not result in a concomitant decrease in apparent permeability as demonstrated in PAMPA, rat intestinal perfusion, and Caco-2 models $(17,18)$. This is in contrast to other solubility-enhancing techniques such as excipient complexation (cyclodextrins, surfactant micellization) or cosolvent solubilization where the apparent increase in solubility is hampered by an apparent decrease in permeability, limiting the overall rate and extent of oral absorption (19-21). Finally, the preference for a solid dosage form and corresponding established manufacturing processes is driving the adoption of ASDs $(22,23)$.

ASDs are primarily manufactured by solvent evaporation or thermal (fusion) methods $(12,23)$. Spray drying is the principal technology used in the solvent evaporation method as it is well established and the rapid evaporation rate lends itself well to forming ASDs (24). In this process, the drug, polymer, and potentially other excipients are dissolved in a suitable solvent and sprayed through a nozzle into a stream of drying gas. The rapid evaporation and presence of the polymer leads to a rapid viscosity increase that kinetically traps the amorphous drug in the polymer matrix (24). The collected material is typically dried further in a batch step to remove residual solvent. Additional benefits include the scalability of the process and the ability to engineer particles to desired morphologies (25). However, spray drying is not without its challenges. The use of organic solvents in particular can be costly from a raw materials and explosion risk-mitigation perspective. Additionally, given the toxicity, added quality controls are required to ensure the residual levels of solvent are below 
regulatory requirements (USP Monograph $<467>$ Residual Solvents) (26). The alternative to solvent evaporation methods for producing ASDs is the use of thermal, or fusion, processing methods (27), particularly hot-melt extrusion (2831). A number of other thermal processing methods have been described in the literature including melt mixing, spray congealing, sintering/curing, melt granulation, and injection molding (27); however, this review will focus on hot-melt extrusion and KinetiSol processing technologies.

Hot-melt extrusion (HME) is a manufacturing process adapted from the plastics industry, including single- and twin-screw extruders. Twin-screw extruders are more common for pharmaceutical applications and can be operated in counter-rotating or corotating configurations (32). Typically, solid raw materials are fed into the extruder barrel and the screws perform the operations of conveying, mixing, and softening or melting (33). The softened material is then forced through a die for shaping and downstream processing. In processing ASDs, the drug is melted or solubilized in the polymeric carrier and the rapid cooling and high viscosity results in a thermodynamically or kinetically stabilized amorphous dispersion (11). The Meltrex ${ }^{\circledR}$ platform commercialized by Soliqs and AbbVie is perhaps the most well-known example of HME-enabled products in the pharmaceutical industry, including the solid oral dosage forms of Kaletra ${ }^{\circledR}$ and Norvir ${ }^{\circledR}$ for treatment of HIV (34), the recently approved Viekirax ${ }^{\circledR}$ for treatment of $\operatorname{HCV}(35,36)$, and other products in development for oncology indications (37). In addition, other pharmaceutical companies have adopted hot-melt extrusion technology with the recent approvals of Onmel ${ }^{\circledR}$ by Merz Pharmaceuticals and Noxafil ${ }^{\circledR}$ by Merck \& Co (38-40). Despite this recent commercial success of HME for pharmaceutical applications, a number of challenges still exist, particularly for thermally labile drugs and polymers, as well as viscosity limitations for a number of pharmaceutical polymer carriers.

This review will outline the thermal and rheological processing windows, or lack thereof, of common pharmaceutical polymers for HME processing. This will be followed by a review of formulation and process-driven strategies being investigated to further enable thermal processing of a wider range of compositions. Expanding the compositions that can be thermally processed will aid in finding the optimal stabilizers for ASDs in both the solid state and during dissolution in the gastrointestinal tract. Additionally, alternative carriers can provide modified release properties as may be required for a particular product's target profile.

\section{EXTRUSION-PROCESSING WINDOWS OF COMMON POLYMER CARRIERS}

As described, HME is the most common thermal processing method for the production of ASDs in the pharmaceutical industry. Identifying suitable extrusion parameters is highly formulation dependent (41). The physicochemical properties of the API must be considered including the glass transition and melting temperatures, the degradation temperature, and the miscibility or solubility of the API in the polymer carrier (42-44). The polymer carrier is often the predominant component within the formulation, and only a limited number of carrier options are approved for pharmaceutical use. Thus, the physicochemical properties of the polymer carrier often have the greatest influence in defining processing conditions. The two major factors of the polymer carrier to consider when identifying an extrusion-processing window are its degradation temperature and viscoelastic properties (45).

The degradation temperature of the polymer can grossly be defined by weight loss in thermogravimetric analysis, which establishes an upper temperature limit for extrusion processing. Notably, chemical degradation without weight loss can occur at lower temperatures and the effects of shear stress are not accommodated by this analysis, but at least a starting reference temperature is established for the maximum. Next, the viscoelastic properties of the polymer must be investigated in terms of the torque limitations of extrusion processing. The viscoelastic properties of a polymer can be described in terms of its storage modulus $\left(G^{\prime}\right.$, how elastic or solid-like the polymer is) and its loss modulus ( $G^{\prime \prime}$, how viscous or liquid-like the polymer is). The loss tangent is the ratio of the loss modulus to the storage modulus $\left(G^{\prime \prime} / G^{\prime}\right)$, and a value of 1 represents the transition point from solid-like to liquid-like properties. The sum of the storage modulus and loss modulus is the complex modulus, which represents the overall resistance to deformation. Finally, the complex viscosity $(\eta)$ represents the frequency dependence on melt viscosity, which typically decreases with increasing frequencies, or shear, in pharmaceutical polymers. The complex viscosity of neat polymer can be measured by melt rheology and have been correlated to torque limitations in extrusion processing (45). A complex viscosity between 10,000 and $1000 \mathrm{~Pa}$ s has been correlated to extrusionprocessing capabilities with $10,000 \mathrm{~Pa}$ s being too solid-like and exceeding the torque limitations of a small-scale extruder and $1000 \mathrm{~Pa}$ s being too liquid-like to shape through an extruder die (46). A temperature range corresponding to the complex viscosity range between 10,000 and $1000 \mathrm{~Pa}$ s establishes the baseline extrusion-processing window when this temperature range is between the glass transition and the degradation temperatures ( $T_{\mathrm{g}}$ and $T_{\mathrm{deg}}$, respectively) of the polymer.

In the following subsections, the extrusion-processing windows of three common classes of pharmaceutical polymers will be reviewed. The data was predominantly obtained by a series of valuable papers from the group of Dr. Serajuddin (46-48), along with vendor information and other sources as identified.

\section{Polyvinyl-Based Polymers}

Polyvinyl-based polymers such as polyvinylpyrrolidone (PVP), polyvinyl pyrrolidone-vinyl acetate copolymer (PVP VA64), and poly(vinyl carprolactam-co-vinylacetate-ethylene glycol) (Soluplus ${ }^{\circledR}$ ) have been widely studied and utilized as carriers for amorphous solid dispersions. Polyvinyl-based polymers are fully synthetic with properties that vary in relation to different degrees of polymerization. PVP is a linear polymer consisting of 1-vinyl-2-pyrrolidone groups and is available in a variety of grades based on the degree of polymerization, expressed as a $K$ value that corresponds to a molecular weight range between 2500 and 3,000,000 $\mathrm{Da}$ (49). The polymer backbone contains carbonyl groups that can act as proton acceptors, which can interact with molecules containing proton donor groups for enhanced physical stability (50). PVP has 
successfully been utilized in marketed amorphous solid dispersions in the product Rezulin ${ }^{\mathrm{TM}}$, which was subsequently withdrawn due to toxicology concerns of the active ingredient (51) and in fast-acting ibuprofen (52). Copovidone (PVP VA64) is a block copolymer of 1-vinyl-2-pyrrolidone and vinyl acetate in a 3:2 ratio and is only available in one grade with a nominal $K$ value of 28 (49). The lower glass transition temperature and hygroscopicity of PVP VA64 compared to PVP is more amenable from a processing and stability perspective. It has been successfully utilized in a number of studies to produce stable ASDs and is the polymer carrier used in Meltrex ${ }^{\circledR}$ products (34).

The glass transition and/or melting temperature, the degradation temperature, and the extrusion temperature range based on viscoelastic properties as previously described of polyvinyl-based polymers are shown in Table I $(45,46)$. Polymers such as copovidone, Soluplus ${ }^{\circledR}$, and Kollicoat IR have a wide extrusion temperature range of more than $20^{\circ} \mathrm{C}$, offering greater flexibility in processing. Lower molecular weight grades of PVP have a narrow processing window, and higher molecular weight grades are too viscous to be processed below their degradation temperatures. Plasticization by the drug or another excipient, or other processing strategies, would be necessary in order to utilize the higher molecular weight grades of PVP.

\section{Cellulose-Based Polymers}

Cellulose is the most abundant natural polymer consisting of linked D-glucose units. Derivatives of cellulose based on reactions of the hydroxyl groups are among the most studied polymers for pharmaceutical use. Example polymers include hydroxypropyl methylcellulose (HPMC), hydroxypropyl cellulose (HPC), hydroxypropyl methylcellulose acetate succinate (HPMC AS), hyroxypropyl methylcellulose phthalate (HPMC P), and ethylcellulose (EC). HPMC is available in a variety of grades consisting of different degrees of hydroxyl and methyl substitution and a wide range of molecular weights (49). HPMC exhibits unique thermal gelation properties, which vary depending on chemistry and molecular weight and have been exploited for controlled release applications (53). The available hydrogen bond donors of the hydroxyl groups in HPMC are also ideal for stabilizing amorphous drugs with available hydrogen bond acceptors. Other derivatives such as HPMC AS and HPMC P offer modified drug release to different sites in the gastrointestinal tract based on differences in $\mathrm{pH}$ solubility. Such $\mathrm{pH}$-dependent release is especially useful for delivering drugs that are acid labile (54) or when targeting higher concentrations of the drug in the small intestines (55). In summary, cellulose derivatives are extremely versatile for use in drug delivery applications and have been widely studied and commercially accepted in formulating amorphous solid dispersions such as in the cases of Onmel ${ }^{\mathrm{TM}}$ and Zelboraf ${ }^{\mathrm{TM}}(56,57)$.

The glass transition and/or melting temperature, the degradation temperature, and the extrusion temperature range of some common cellulose-based polymers are shown in Table II (48). Of the polymers tested, only HPC exhibited a wide extrusion-processing window of $>20^{\circ} \mathrm{C}$. Various grades of EC exhibited narrow processing windows of $\sim 5$ to $15^{\circ} \mathrm{C}$, and various grades of HPMC, HPMC AS, HPMC P, and methylcellulose exhibited no processing window below the degradation temperature, representing a significant challenge.

\section{Polymethacrylate-Based Polymers}

Polymethacrylates encompass a group of synthetic, ionic polymers with varying ratios of dimethylaminoethyl methacrylates, methacrylic acid, and methacrylic acid esters (49). These polymers have historically been used as film-coating agents but have gained interest as carriers in ASDs in recent years due to their ionic characteristics that allow for targeted drug delivery along the gastrointestinal tract (58). They are commonly referred to by the trade name Eudragit $₫$ with Eudragit ${ }^{\circledR}$ E soluble at $\mathrm{pH}>5$, Eudragit ${ }^{\circ}$ L100-55 soluble at $\mathrm{pH}>5.5$, Eudragit ${ }^{\circledR}$ L soluble at $\mathrm{pH}>6$, and Eudragit ${ }^{\circledR} \mathrm{S}$ soluble at $\mathrm{pH}>7$. Additionally, sustained release grades are available as Eudragit ${ }^{\circledR}$ RL, Eudragit ${ }^{\circledR}$ LS, and Eudragit ${ }^{\circledR}$ NE.

The glass transition and/or melting temperature, the degradation temperature, and the extrusion temperature range of some common polymethacrylate-based polymers are shown in Table III (47). Interestingly, the homo block copolymers Eudragit ${ }^{\circledR}$ E PO, Eudragit ${ }^{\circ}$ RL PO, and Eudragit $₫$ RS PO exhibited extrusion-processing windows, but the hetero block copolymers Eudragit ${ }^{\circledR}$ L100, Eudragit ${ }^{\circ}$ S100, and Eudragit ${ }^{\circledR}$ L100-55 were too viscous to be extruded as neat polymers.

Table I. Thermal Properties and Extrusion Temperature Ranges of Polyvinyl Polymers (Star Denotes Lack of Extrusion Temperature Range)

\begin{tabular}{|c|c|c|c|c|}
\hline Chemical name (MW in $\mathrm{g} / \mathrm{mol})$ & Abbreviation/trade name & $T_{\mathrm{g}}, T_{\mathrm{m}}\left({ }^{\circ} \mathrm{C}\right)$ & $T_{\mathrm{deg}}\left({ }^{\circ} \mathrm{C}\right)$ & $\begin{array}{l}\text { Extrusion temperature } \\
\text { range }\left({ }^{\circ} \mathrm{C}\right)\end{array}$ \\
\hline Polyvinylpyrrolidone (MW 2000-3000) & PVP K12 & 72 & 196 & $152-167$ \\
\hline Polyvinylpyrrolidone (MW 7000-11,000) & PVP K17 & 140 & 217 & $175-185$ \\
\hline Polyvinylpyrrolidone (MW 28,000-34,000) & PVP K25 & 153 & 166 & $*$ \\
\hline Polyvinylpyrrolidone (MW 44,000-54,000) & PVP K30 & 160 & 171 & * \\
\hline Polyvinylpyrrolidone (MW 1,000,000-1,500,000) & PVP K90 & 177 & 194 & $*$ \\
\hline Vinylpyrrolidone/vinylacetate (6:4) (MW 45,000-70,000) & PVP VA64 & 105 & 270 & $157-177$ \\
\hline $\begin{array}{l}\text { Poly(vinyl carprolactam-co-vinylacetate-ethylene glycol) } \\
\text { (MW 900,000-140,000) }\end{array}$ & Soluplus ${ }^{\circledR}$ & 72 & 278 & $142-166$ \\
\hline $\begin{array}{l}\text { Polyvinyl alcohol-polyethylene glycol graft copolymer } \\
\text { (MW } \sim 45,000)\end{array}$ & Kollicoat IR & 45,208 & 200 & $155-185$ \\
\hline
\end{tabular}

Adapted from (46) and (45)

$M W$ molecular weight, $T_{g}$ glass transition temperature, $T_{m}$ melt temperature, $T_{\text {deg }}$ degradation temperature 
Table II. Thermal Properties and Extrusion Temperature Ranges of Cellulosic Polymers (Star Denotes Lack of Extrusion Temperature Range)

\begin{tabular}{|c|c|c|c|c|}
\hline Chemical name (MW in $\mathrm{g} / \mathrm{mol}$ ) & Abbreviation/trade name & $T_{\mathrm{g}}, T_{\mathrm{m}}\left({ }^{\circ} \mathrm{C}\right)$ & $T_{\operatorname{deg}}\left({ }^{\circ} \mathrm{C}\right)$ & $\begin{array}{l}\text { Extrusion temperature } \\
\text { range }\left({ }^{\circ} \mathrm{C}\right)\end{array}$ \\
\hline Hydroxypropyl methylcellulose, 6 cps (MW 10,000) & HPMC $29106 \mathrm{cps}$ & 139 & 244 & $*$ \\
\hline Hydroxypropyl methylcellulose, 100 cps (MW 25,000) & HPMC K100LV & 168 & 259 & $*$ \\
\hline Hydroxypropyl methylcellulose, 100,000 cps (MW 150,000) & HPMC K100M & 173 & 259 & * \\
\hline $\begin{array}{l}\text { Hydroxypropyl methylcellulose acetate succinate, } 3 \mathrm{cps} \\
\text { (MW 18,000) }\end{array}$ & HPMC AS MF & 122 & 204 & $*$ \\
\hline $\begin{array}{l}\text { Hydroxypropyl methylcellulose phthalate, } 40 \mathrm{cps} \\
\text { (MW 45,600) }\end{array}$ & HPMC P HP-55 & 147 & 194 & $*$ \\
\hline $\begin{array}{l}\text { Hydroxypropyl methylcellulose phthalate, } 55 \mathrm{cps} \\
\text { (MW 37,900) }\end{array}$ & HPMC P HP-50 & 143 & 199 & $*$ \\
\hline Methylcellulose, 15 cps (MW 14,000) & MC $15 \mathrm{LV}$ & 175 & 247 & $*$ \\
\hline Hydroxypropyl cellulose (MW 95,000) & HPC LF & 111 & 227 & $170-200$ \\
\hline Ethylcellulose, $4 \mathrm{cps}$ & $\mathrm{EC} 4 \mathrm{p}$ & 128,168 & 200 & 184-198 \\
\hline Ethylcellulose, $7 \mathrm{cps}$ & EC 7p & 128,168 & 205 & $192-200$ \\
\hline Ethylcellulose, $10 \mathrm{cps}$ & EC 10p & 132,172 & 205 & $195-200$ \\
\hline
\end{tabular}

Adapted from (48)

$M W$ molecular weight, $T_{g}$ glass transition temperature, $T_{m}$ melt temperature, $T_{\text {deg }}$ degradation temperature

\section{Summary}

Among the polymers investigated in all three classes, more than $50 \%(13 / 25)$ could not be processed as neat polymer by HME. It is worth noting that as these windows are defined for neat polymers, many polymers that exhibit viscosities just above the defined maximum viscosity limit will be sufficiently plasticized with the addition of API to bring down the viscosity to extrudable levels. For example, low molecular weight grades of HPMC and HPMC AS have been extensively investigated by hot-melt extrusion in ASDs (57,59-61). Additionally, the complex viscosity range was correlated to the torque limitation for a small-scale extruder, and higher torque capacity will often be achievable in larger scale extruders. However, early-phase formulations developed at small scale will generally determine later stage formulation compositions, as significant changes in composition between phases are not preferred. In cases where the API is not able to sufficiently plasticize the polymer carrier, alternative formulation or processing strategies will be necessary to utilize a particular carrier. Additionally, for polymer carriers that exhibit an extrusion-processing window at relatively high temperatures, processing of thermally labile APIs becomes less feasible. The following section will review various strategies being investigated to expand thermal processing capabilities along with their benefits and limitations.

\section{THERMAL PROCESSING STRATEGIES}

\section{Incorporation of Plasticizers and Plasticizing Surfactants}

The addition of plasticizers as a strategy to facilitate the extrusion processing is well established in the plastics and pharmaceutical industries (62). Plasticizers are typically small molecules that act to increase the free volume between polymer chains, resulting in a depression of the $T_{\mathrm{g}}$ and the melt viscosity (63). Incorporation of plasticizers is not limited to improving processing but may be incorporated to alter the physicochemical properties of the final product (e.g., mechanical, release rate, etc.). A list of common pharmaceutical plasticizers is shown in Table IV.

Most of the plasticizers in Table IV are liquid at room temperature and would require liquid injection or a wet granulation step prior to extrusion. Alternatively, solid-state

Table III. Thermal Properties and Extrusion Temperature Ranges of Polymethacrylate-Based Polymers (Star Denotes Lack of Extrusion Temperature Range)

\begin{tabular}{|c|c|c|c|c|}
\hline Chemical name (MW in $\mathrm{g} / \mathrm{mol})$ & $\begin{array}{l}\text { Abbreviation/ } \\
\text { trade name }\end{array}$ & $T_{\mathrm{g}}, T_{\mathrm{m}}\left({ }^{\circ} \mathrm{C}\right)$ & $T_{\mathrm{deg}}\left({ }^{\circ} \mathrm{C}\right)$ & $\begin{array}{l}\text { Extrusion temperature } \\
\text { range }\left({ }^{\circ} \mathrm{C}\right)\end{array}$ \\
\hline $\begin{array}{l}\text { Butyl methacrylate/dimethylamino ethyl methacrylate/methyl } \\
\text { methacrylate (1:2:1) (MW 47,000) }\end{array}$ & Eudragit $®$ EPO & 52 & 250 & $127-150$ \\
\hline $\begin{array}{l}\text { Ethyl acrylate/methyl methacrylate/trimethylammonioethyl } \\
\text { ethacrylate chloride (1:2:0.2) (MW 32,000) }\end{array}$ & Eudragit ${ }^{\circledR}$ RL PO & 63 & 166 & $165-170$ \\
\hline $\begin{array}{l}\text { Ethyl acrylate/methyl methacrylate/trimethylammonioethyl } \\
\text { methacrylate chloride (1:2:0.1) (MW 32,000) }\end{array}$ & Eudragit $®$ RS PO & 64 & 170 & $142-167$ \\
\hline Methacrylic acid/methyl methacrylate (1:1) (MW 125,000) & Eudragit $®$ L100 & 195 & 176 & $*$ \\
\hline Methacrylic acid/methyl methacrylate (1:2) (MW 125,000) & Eudragit@ S100 & 173 & 173 & $*$ \\
\hline Methacrylic acid/ethyl acrylate (1:1) (MW 320,000) & Eudragit ${ }^{\circledR}$ L100-55 & 111 & 176 & $*$ \\
\hline
\end{tabular}

Adapted from (47)

$M W$ molecular weight, $T_{g}$ glass transition temperature, $T_{m}$ melt temperature, $T_{\text {deg }}$ degradation temperature 
Table IV. Common Plasticizers Used in Pharmaceutical Dosage Forms

\begin{tabular}{|c|c|}
\hline Type & Examples \\
\hline Citrate esters & $\begin{array}{l}\text { Triethyl citrate, tributyl citrate, acetyl triethyl } \\
\text { citrate, acetyl tributyl citrate }\end{array}$ \\
\hline Fatty acid esters & $\begin{array}{l}\text { Butyl stearate, glycerol monostearate, stearyl } \\
\text { alcohol }\end{array}$ \\
\hline Sebacate esters & Dibutyl sebacate \\
\hline Phthalate esters & $\begin{array}{l}\text { Diethyl phthalate, dibutyl phthalate, dioctyl } \\
\text { phosphate }\end{array}$ \\
\hline Glycol derivatives & Polyethylene glycol, propylene glycol \\
\hline Vitamin E TPGS & $\begin{array}{l}\text { d- } \alpha \text {-Tocopheryl polyethylene glycol } 1000 \\
\text { succinate }\end{array}$ \\
\hline Other & Triacetin, mineral oil, castor oil \\
\hline
\end{tabular}

Adapted with permission from (31)

plasticizers such as methylparaben and citric acid have been investigated to reduce the number of processing steps $(64,65)$. Many of these plasticizers have been shown to be effective at reducing the melt viscosity of viscous polymers to extrudable levels (66-68). For example, triethyl citrate (TEC), methylparaben (MP), polyethylene glycol 8000 (PEG 8000), citric acid monohydrate ( $\mathrm{CA} \mathrm{MH})$, and acetyltributyl citrate (ATBC) were investigated for plasticization efficiency and preservation of the delayed drug release properties in Eudragit ${ }^{\circledR}$ S100 matrix pellets (67). As described previously, Eudragit ${ }^{\circledR}$ S100 did not exhibit an extrusion-processing window below its degradation temperature. TEC, MP, and PEG 8000 were found to be the most efficient plasticizers for Eudragit ${ }^{\circledR}$ S100, while TEC and MP were most efficient at maintaining the enteric properties of the polymer due to their limited water solubility (67). This was shown to be independent of plasticizer level between 10 and 20\% (68). Similarly, TEC and PEG 6000 were investigated as plasticizers in ethyl cellulose matrix tablets (66). As previously described, ethyl cellulose $10 \mathrm{cps}$ was shown to have a narrow extrusion-processing window of 195 to $200^{\circ} \mathrm{C}$. The plasticizing efficiency TEC and PEG600, along with two APIs, zidovudine (AZT) and lamivudine (3TC), is shown in Fig. 1. PEG 6000 and more so, TEC, were able to reduce the complex viscosity to levels below $10,000 \mathrm{~Pa} \mathrm{~s}$ at a temperature of $150^{\circ} \mathrm{C}$. This was true for as little as 5 to $10 \%$ plasticizer in the case of TEC.

More recently, surfactants have been evaluated as plasticizers for several common polymer systems such as PVP K30, PVP VA64, HPMC E5, HPMC AS, and Eudragit@ L100 (69). The surfactant systems evaluated included polysorbate 80 , docusate sodium, polyoxyethylene (40) stearate, pluronic F68, and sodium lauryl sulfate. In extrusion experiments, polysorbate 80 was found to be the most effective plasticizer due to its low $T_{\mathrm{g}}$ (liquid at RT), followed by docusate sodium. The other surfactants were not very effective as plasticizers. In a stability study of solid dispersions containing surfactants by the same group, the influence of the surfactant on physical stability was investigated (70). The addition of surfactant in HPMC E5 compositions resulted in crystallization when stored at $30^{\circ} \mathrm{C} / 65 \% \mathrm{RH}$, but no difference was observed between samples with and without surfactant in PVP or PVP VA64 compositions.

The impact of surfactant addition in solid dispersions has been extensively studied by the group of Dr. Van den Mooter
(71-74). In one study, the surfactant TPGS 1000 was incorporated into solid dispersions containing an experimental antiviral compound, UC781, and either PVP VA64 or HPMC 2910 resulting in more rapid dissolution rates as the surfactant concentration was increased in solid dispersion granules (75). TPGS 1000 was also evaluated in solid dispersions containing itraconazole and PVP VA64 (73). Itraconazole was found to have improved the maintenance of supersaturation relative to the presence of PVP VA64 or TPGS 1000 alone and, thus, was formulated together in a ternary solid dispersion. This was shown to be ineffective, however, as the addition of TPGS 1000 resulted in phase separation and crystallization of itraconazole.

Specific effects of the addition of surfactants on crystal growth have been investigated. In studies evaluating ritonavir crystal growth rates in the presence of polymers, surfactants, and polymer-surfactant combinations, the inclusion of surfactants alone accelerated crystal growth rates, and surfactantpolymer blends were shown to decrease the effectiveness of cellulosic polymers to retard crystal growth (76). A similar increase in crystal growth rates was observed in studies with amorphous celecoxib in which most miscible surfactants increased the growth rate at low temperatures (77). However, this was found to be dependent on the polymer as well, with PVP slowing the acceleration of the crystal growth rate by the surfactants. It is worth noting, however, that these studies were performed above the $T_{\mathrm{g}}$ of the system where molecular mobility is high and, thus, may not be representative of crystal growth below $T_{\mathrm{g}}$. Similarly, it is unclear if this effect would translate during supersaturation or nonsink dissolution experiments.

The addition of surfactants can also be leveraged in ASDs to facilitate stability of nano/microdispersions formed in situ from the melt-extruded drug product once dispersed in aqueous media, as in the case of ritonavir and lopinavir extrudate produced by Meltrex ${ }^{\circledR}$ technology $(78,79)$. In situ formation of nanoparticles released from the drug product has been shown to enhance dissolution rates and the use of surfactants can aid in the prevention of coalescence of these aggregates, with charge repulsion identified as a likely mechanism (80).

The addition of plasticizers to facilitate thermal processing must be balanced with potential negative consequences. Particularly for ASDs, the increase in free volume and molecular mobility by a plasticizer has been shown to result in decreased physical stability compared to dispersions of the drug and polymer $(73,81)$. In such cases, alternative strategies may be needed to enable processing of ASDs with the target profile.

\section{Temporary Plasticizers and Supercritical Technology}

In the last decade, temporary plasticizers have been investigated as an alternative to traditional plasticizers in pharmaceutical extrusion. A temporary plasticizer generally refers to the injection of supercritical carbon dioxide $\left(\mathrm{sc}-\mathrm{CO}_{2}\right)$ into the extrusion process (82). sc- $\mathrm{CO}_{2}$ exhibits high plasticization efficiency in polymers that have high $\mathrm{CO}_{2}$ solubility (83), with the added benefit that expansion of sc- $\mathrm{CO}_{2}$ upon exiting the extrusion process results in the complete removal of $\mathrm{CO}_{2}$ from the final product (82). Thus, the composite $\mathrm{T}_{\mathrm{g}}$ of the final product is not depressed and molecular mobility is not 

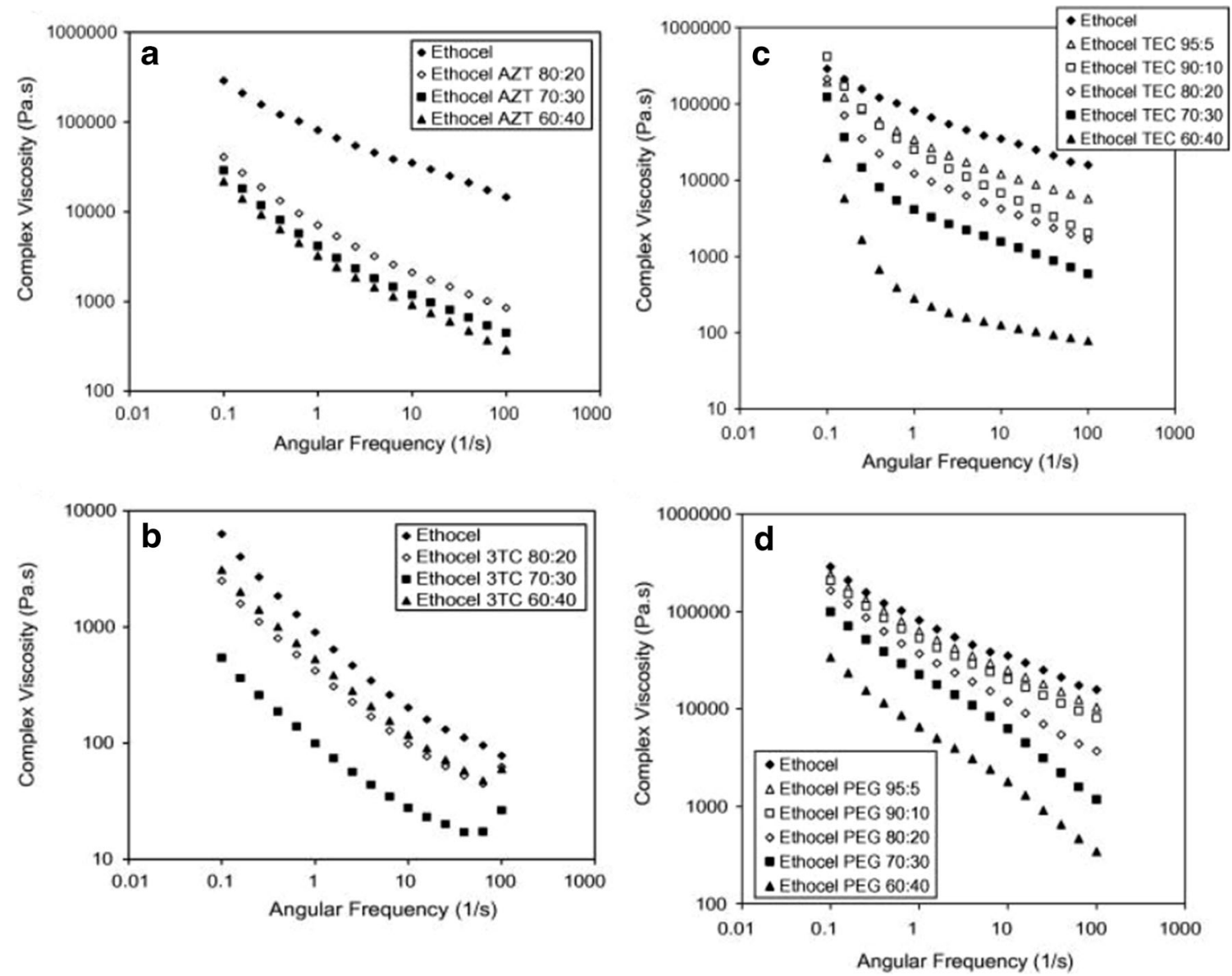

Fig. 1. Complex viscosity of a ethyl cellulose and zidovudine (AZT) blends at $150^{\circ} \mathrm{C}$, b ethyl cellulose and lamivudine (3TC) blends at $165^{\circ} \mathrm{C}$, c ethyl cellulose and TEC blends at $150^{\circ} \mathrm{C}$, and $\mathbf{d}$ ethyl cellulose and PEG 6000 blends at $150^{\circ} \mathrm{C}$. Reproduced with permission from (66)

increased within the matrix. Additionally, the lack of a plasticizer component in the final formulation will allow for a lower drug product weight and size, or fewer dosages, fostering patient compliance. Plasticization by sc- $\mathrm{CO}_{2}$ occurs due to an increase in free volume by absorption of $\mathrm{CO}_{2}$ between polymer chains as well as acting as a molecular lubricant (83). sc$\mathrm{CO}_{2}$ can also act as a temporary cosolvent that is environmentally friendly (84). A schematic of a supercritical injection system retrofitted to a twin-screw extruder is shown in Fig. 2 (85). The chiller and pump assist in maintaining a temperature of $31^{\circ} \mathrm{C}$ and a pressure of 74 bar necessary to convert $\mathrm{CO}_{2}$ gas to a supercritical fluid (63). Due to the plasticizing effect and subsequent expansion of $\mathrm{CO}_{2}$ upon ejection from the die, the extrudate will be porous (foamed) and other morphology changes may occur such as crystallization of certain polymers (82).

The plasticization efficiency of sc- $\mathrm{CO}_{2}$ has been evaluated with multiple pharmaceutical polymers, including PVP VA64, Eudragit@ E, and EC $20 \mathrm{cps}$ (86). A number of aspects related to $\mathrm{CO}_{2}$ injection in melt extrusion were described including using conveying elements at the site of injection, forming a melt seal upstream of injection to prevent leakage, maintaining high pressure downstream of injection with die resistance to facilitate and maintain $\mathrm{CO}_{2}$ dissolution in the polymer, and using kneading elements downstream of injection to adequately mix and dissolve $\mathrm{CO}_{2}$. After optimizing extrusion conditions, it was found that $\mathrm{CO}_{2}$ could be injected at subcritical conditions for PVP VA64 and Eudragit ${ }^{\circ} \mathrm{E}$, resulting in a $30^{\circ} \mathrm{C}$ and $15^{\circ} \mathrm{C}$ reduction in extrusion-processing temperatures, respectively. Thermal analysis of the milled extrudate revealed no differences in glass transition temperatures with or without $\mathrm{CO}_{2}$ injection. For EC $20 \mathrm{cps}, \mathrm{CO}_{2}$ could be injected at supercritical conditions, resulting in a more significant $65^{\circ} \mathrm{C}$ reduction in extrusion temperature. However, while thermal analysis showed no change in $T_{\mathrm{g}}$ between EC extrudate processed with and without $\mathrm{CO}_{2}$ injection, a change in melt enthalpy was observed. EC $20 \mathrm{cps}$ processed with $\mathrm{CO}_{2}$ exhibited an increased enthalpy relative to the polymer processed without $\mathrm{CO}_{2}$ injection. This was attributed to the increased mobility of the polymer in the presence of $\mathrm{CO}_{2}$, allowing for alignment of polymer chains, as has been observed and described by others in semicrystalline polymers such as PEO (87,88). Finally, each of the polymers investigated exhibited increased dissolution rates when processed with $\mathrm{CO}_{2}$ injection due to the increased porosity and foaming effect of the expanding gas upon exiting the extruder die. Other investigators have found that the pore size is a function of the processing temperature and $\mathrm{CO}_{2}$ concentration (89).

Further studies were performed with PVP VA64 and EC $20 \mathrm{cps}$ with itraconazole to demonstrate the utility of $\mathrm{CO}_{2}$ injection as a temporary plasticization method in the 


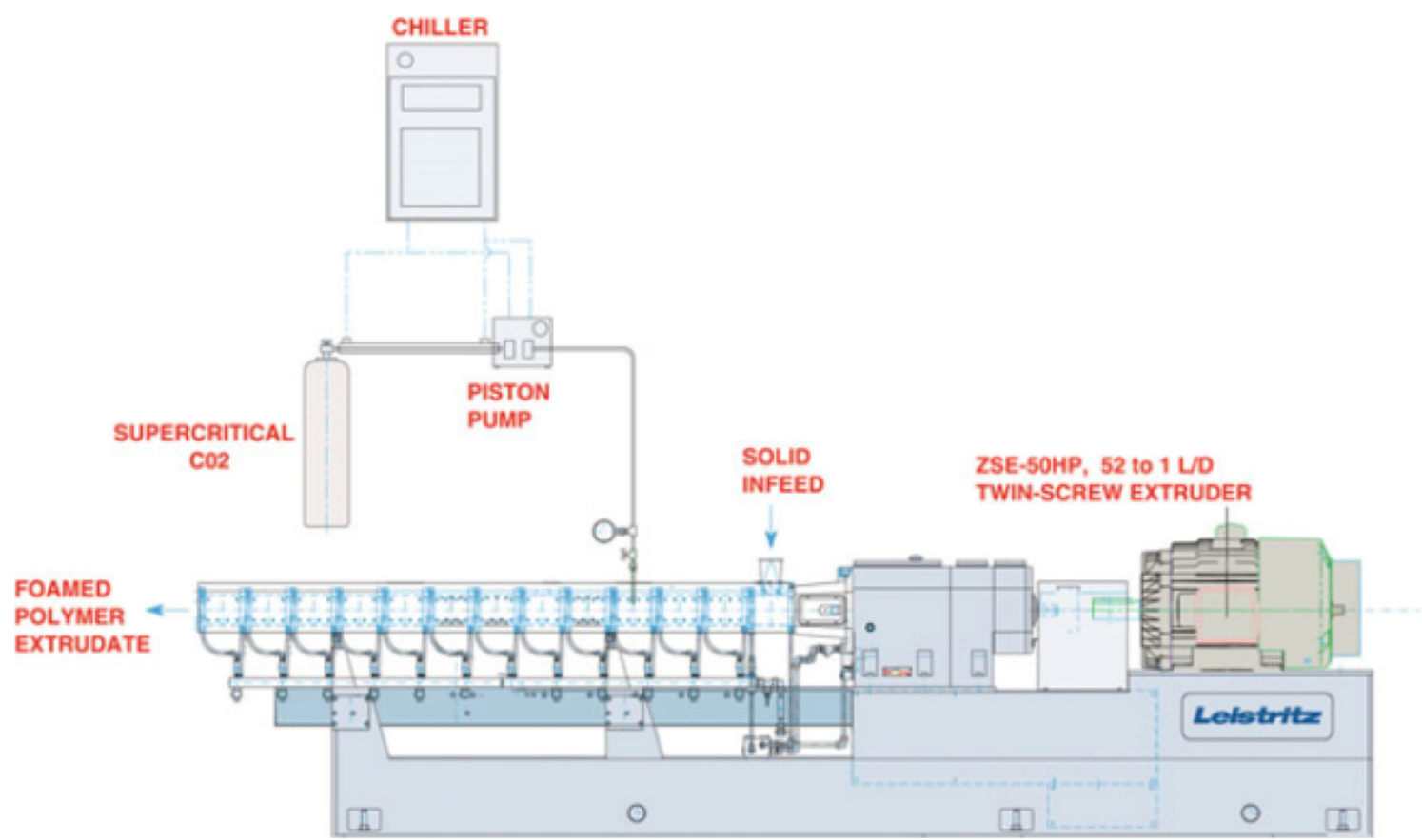

Fig. 2. Schematic of a twin-screw extrusion supercritical injection system. Reproduced with permission from (85)

production of ASDs $(90,91)$. Injection of $\mathrm{CO}_{2}$ resulted in efficient plasticization with a corresponding reduction in processing temperature. For PVP VA64 compositions, the dissolution with and without $\mathrm{CO}_{2}$ injection was comparable, with only a minor increase in initial wetting for samples processed without $\mathrm{CO}_{2}$ injection (91). Conversely, a notable increase in dissolution rate was observed in EC samples processed with $\mathrm{CO}_{2}$ injection (90). In both polymer systems, an increase in surface area and porosity was observed with $\mathrm{CO}_{2}$ injection, resulting in an increased milling efficiency of the extrudate intermediate. The benefits of $\mathrm{sc}-\mathrm{CO}_{2}$ injection were further demonstrated in the extrusion of EC $20 \mathrm{cps}$ with a thermally labile API, $p$-amino salicylic acid ( $p$-ASA) (92). p-ASA substantially degrades above $120^{\circ} \mathrm{C}$ but is stable for at least $10 \mathrm{~min}$ at atmospheric conditions below $110^{\circ} \mathrm{C}$. Without $\mathrm{CO}_{2}$ injection, the minimum extrusion temperature of a $10 \%(w / w)$ p-ASA/EC $20 \mathrm{cps}$ blend was $130^{\circ} \mathrm{C}$, which resulted in $17 \%$ decomposition of the API. With $\mathrm{CO}_{2}$ injection, the blend could be extruded at temperatures at or below $110^{\circ} \mathrm{C}$, resulting in less than $5 \%$ decomposition of $p$-ASA.

Recently, subcritical (pressurized) injection of $\mathrm{CO}_{2}$ was investigated as a temporary plasticizer for ketoprofen and HPC dispersions (93). Plasticization by injection of $\mathrm{CO}_{2}$ enabled a decrease of approximately $20^{\circ} \mathrm{C}$ in extrusion temperature. A milling study was also conducted with HPC extrudates plasticized with propylene glycol (PG) as a comparator, which resulted in torque overload due to their high flexibility and failed to mill. HPC extrudate plasticized with $\mathrm{CO}_{2}$, however, could be efficiently milled (as determined by relative torque values) due to the porous morphology of the extrudate. HPC extrudate processed without any plasticization could be milled with prior storage in a freezer, though not as efficiently. Microscopy images of various grades of HPC with and without pressurized $\mathrm{CO}_{2}\left(\mathrm{P}-\mathrm{CO}_{2}\right)$ injection, or with $\mathrm{PG}$ injection is shown in Fig. 3, highlighting the porous structure of $\mathrm{P}-\mathrm{CO}_{2}$-injected samples. Furthermore, enhanced tableting properties were observed with porous extrudate such as increased hardness and reduced friability.

\section{Designer Polymers for Extrusion Processing}

Owing to the increased importance of HME in pharmaceutical development, many excipient vendors are engineering pharmaceutical-grade polymers specifically designed and marketed for extrusion processing. These polymers tout their performance as crystallization inhibitors and solubility enhancers, while offering a wider temperature range for extrusion processing. The most well-known and earliest example is Soluplus ${ }^{\circledR}$ developed by BASF®, but other vendors are following suit with new extrusion grades of HPMC by Dow ${ }^{\circledR}$ and HPMC AS by Ashland®.

Soluplus ${ }^{\circledR}$ is a polyvinyl caprolactam-polyvinyl acetatepolyethylene glycol graft copolymer (13\% PEG 6000/57\% vinyl caprolactam $/ 30 \%$ vinyl acetate), with PEG 6000 forming the backbone of the polymer (94). The structure of Soluplus ${ }^{\circledR}$ is shown in Fig. 4. The polymer was designed to be both a matrix former and a solubilizer due to its amphiphilic structure (95). It was also designed to be self-plasticizing with a relatively low $T_{\mathrm{g}}$ of $70^{\circ} \mathrm{C}$ to enable extrusion at low temperatures; however, others have shown that Soluplus ${ }^{\circledR}$ still exhibits high complex viscosity above $T_{\mathrm{g}}$ and needs to be processed at temperatures as high as $140^{\circ} \mathrm{C}(96)$. Still, Soluplus ${ }^{\circledR}$ has been shown to enhance solubility to a greater extent for certain APIs relative to other hydrophilic polymers (97). The utility of Soluplus ${ }^{\circledR}$ as a matrix polymer and solubility enhancer in melt-extruded ASDs has been demonstrated for multiple poorly water-soluble drugs, including carbamazepine $(95,96,98)$, fenofibrate (99), simvastatin (100), dronedarone hydrochloride (101), and valsartan (102).

Recently, Dow ${ }^{\circledR}$ has introduced its own line of engineered polymers for HME applications. Cellulosic polymers such as HPMC have historically been difficult to extrude due 

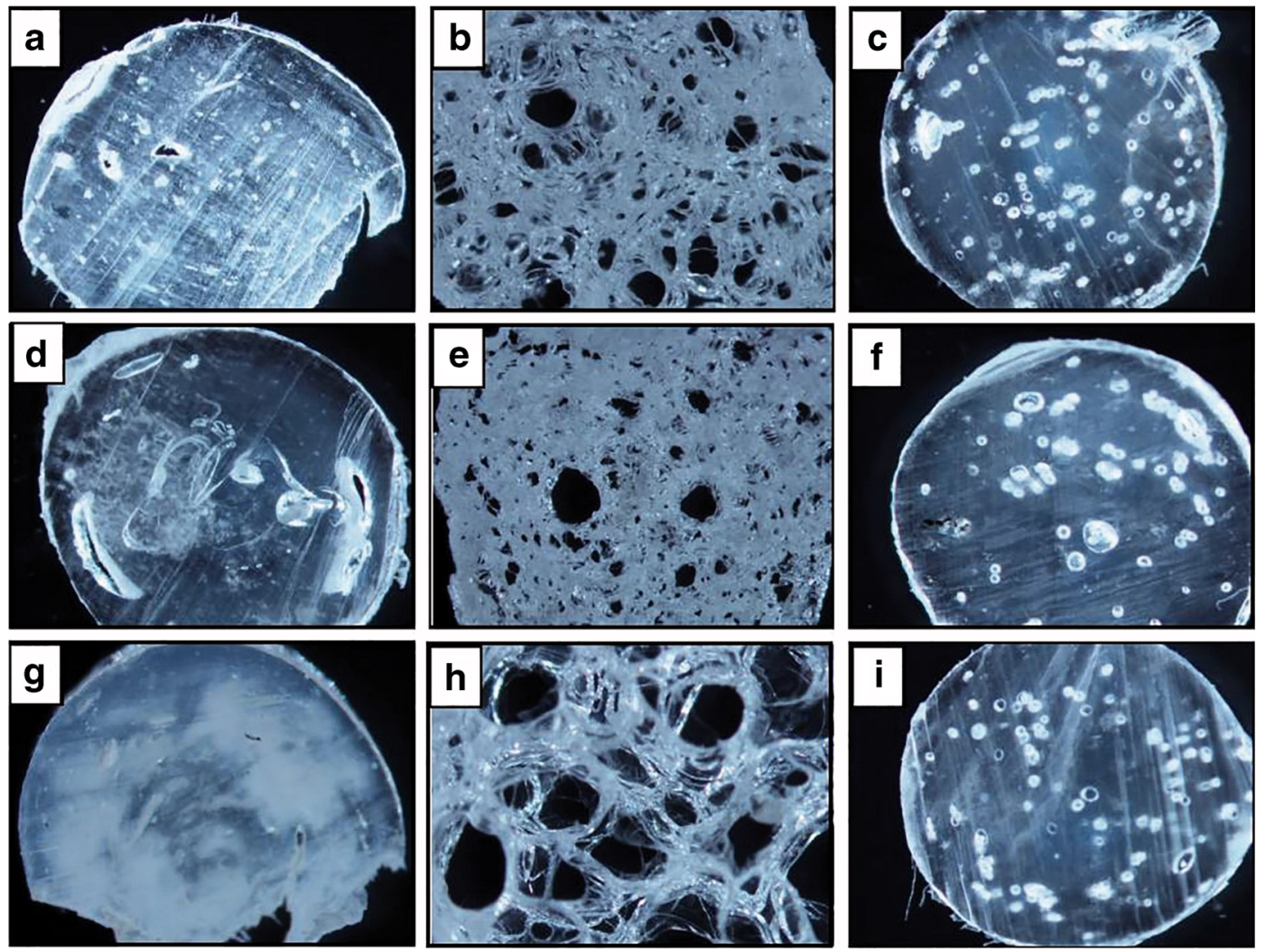

Fig. 3. Microscopy photographs of Klucel_ (ELF, EF, and LF) extrudates with and without $\mathrm{P}_{-} \mathrm{CO}_{2}$ injection, or with $\mathrm{PG}$ injection (magnification $\times 3$ ). a ELF without $\mathrm{P}-\mathrm{CO}_{2}, \mathbf{b}$ ELF with $\mathrm{P}-\mathrm{CO}_{2}, \mathbf{c}$ ELF with PG injection, d EF without P$\mathrm{CO}_{2}$, e EF with $\mathrm{P}-\mathrm{CO}_{2}$, f EF with PG injection, $\mathbf{g} \mathrm{LF}$ without $\mathrm{P}-\mathrm{CO}_{2}, \mathbf{h} \mathrm{LF}$ with $\mathrm{P}-\mathrm{CO}_{2}$, and $\mathbf{i} \mathrm{LF}$ with PG injection. Reproduced with permission from (93)

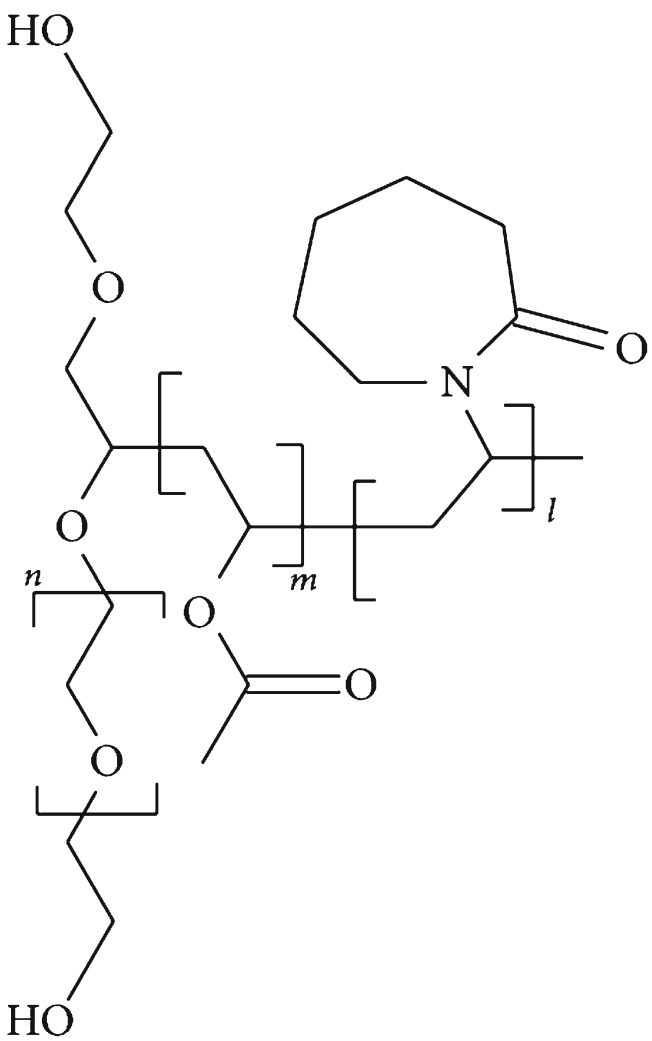

Fig. 4. Chemical structure of polyvinyl caprolactam-polyvinyl acetate-polyethylene glycol graft copolymer (Soluplus ${ }^{\circledR}$ ) to the high melt viscosity and limited extrusion-processing windows, as outlined previously. Even with plasticization by a drug or other additives, HPMC browns at the elevated temperatures often needed for extrusion processing $(49,103)$. Thus, a new line of Affinisol ${ }^{\circledR}$ HPMC polymers have been developed with lower melt viscosity reduced or eliminated discoloration at elevated temperatures (104). The Affinisol ${ }^{\circledR}$ HPMC polymers are available in a variety of molecular weight grades from 3 to $164,000 \mathrm{cP}$ for IR and CR applications and have lower glass transition temperatures ranging from 110 to $130^{\circ} \mathrm{C}(105,106)$. The extrusion-processing windows are much wider and reported to be between 150 and $205^{\circ} \mathrm{C}$ (106). More interestingly, the melt viscosity and corresponding extruder torque load is reported to be independent of the polymer molecular weight, with Affinisol ${ }^{\circledR}$ HPMC $6 \mathrm{LV}$, 100LV, and 4M exhibiting a comparable maximum torque load of approximately $20 \%$ on a Leistritz nano-16 extruder (107). In addition, the crystallization inhibition properties of the polymer remain, with demonstrated dissolution performance of ASDs containing the poorly soluble drugs loratidine (107), carbamazepine (108), and itraconazole (109).

Ashland ${ }^{\circledR}$ has also been investigating a new development grade of the cellulosic polymer HPMC AS for extrusion processing. HPMC AS has been shown to be a very effective crystallization inhibitor in ASDs, which is highly dependent on the ratio of acetyl and succinoyl functional groups. In particular, the level of acetyl groups is the driving force for recrystallization inhibition, which facilitates hydrophobic interactions with poorly water-soluble drugs in solution 
$(55,110)$. Current commercial grades of HPMC AS have a $T_{\mathrm{g}}$ of $120^{\circ} \mathrm{C}$ but often require extrusion temperatures in excess of $170^{\circ} \mathrm{C}$, even with plasticization, to reduce the melt viscosity (111). However, release of acetic and succinic free acid has been shown to occur at temperatures between 180 and $200^{\circ} \mathrm{C}$ (112), resulting in a narrow and relatively high processing window that may exclude thermally labile drugs. Thus, Ashland ${ }^{\circledR}$ has investigated the developmental grades of HPMC AS that have a lower $T_{\mathrm{g}}$ of $\sim 100^{\circ} \mathrm{C}$ and can be extruded at $\sim 140^{\circ} \mathrm{C}$ (111). This investigational grade has also shown to be similar or superior to current commercial grades of HPMC AS in maintaining supersaturation of the poorly soluble drugs nifedipine, itraconazole, and griseofulvin $(111,113)$. It is worth noting that this is currently an investigational polymer and a commercial version has not been introduced at the time of writing.

\section{Thermal Processing by KinetiSol ${ }^{\circledR}$ Dispersing}

Among the thermal processing strategies described thus far, the common method to enable processing of challenging compositions is through a decrease in melt viscosity and composite $T_{\mathrm{g}}$ via plasticization by additives or polymer engineering. Excluding the use of temporary plasticizers, the final product typically has a lower $T_{\mathrm{g}}$, which can impact physical stability in the case of ASDs. An alternative strategy is to approach the challenge from the equipment perspective and utilize processing technologies that are not limited by melt viscosity, which greatly expands thermal processing windows. KinetiSol ${ }^{\circledR}$ Dispersing (KSD) is an emerging processing technology in the pharmaceutical industry that is capable of processing highly viscous and nonthermoplastic materials (114). The KSD process was adapted from the thermokinetic mixers used in the plastics industry (115-117), with modifications for expanded capabilities and permitted use in pharmaceutical applications. The equipment consists of a horizontally mounted processing chamber with a central rotating shaft. A series of mixing blades is mounted to the shaft, which rotates at relatively high velocities (thousands of RPMs). The high velocities impart high frictional forces on the material particles as they impact the walls, blades, and each other. The frictional forces result in a very rapid temperature increase, with general processing times of less than $20 \mathrm{~s}$ (and less than $5 \mathrm{~s}$ at elevated temperatures) to transition drug and polymer blends to a fluxed state, with subsequent discharge at a user-defined set point (114). Example processing profiles are shown in Fig. 5. For small-scale studies, the process is performed in batch mode for quantities between $\sim 50$ and $300 \mathrm{~g}$. The same machine geometry can then be used in semicontinuous mode for throughputs of up to $30 \mathrm{~kg} / \mathrm{h}$. Multiple units can be run in parallel or larger geometry machines can be used for higher throughputs of up to $1000 \mathrm{~kg} / \mathrm{h}$ (114).

The utility of KSD to produce plasticizer-free ASDs with many of the polymer carriers described previously that do not exhibit extrusion-processing windows has been demonstrated. ASDs with Eudragit ${ }^{\circledR}$ L100-55 as the carrier polymer with itraconazole were produced by KSD and compared to similar compositions containing plasticizer (20\% TEC) produced by HME (81). Plasticizer-free compositions exhibited a single $T_{\mathrm{g}}$ of $\sim 101^{\circ} \mathrm{C}$, while those containing plasticizer exhibited a single $T_{\mathrm{g}}$ of $\sim 54^{\circ} \mathrm{C}$. The physical stability of each composition was assessed by placing samples on storage at $40^{\circ} \mathrm{C} / 75 \% \mathrm{RH}$ for 6 months, with the lower $T_{\mathrm{g}}$ compositions containing plasticizer resulting in recrystallization of itraconazole over time. Itraconazole was further evaluated as a model drug in HPMC AS (118) and HPMC E50 (119) compositions produced by KSD. In the latter case of HPMC E50, significantly less polymer degradation and discoloration occurred during KSD processing as compared to compositions that were processed by HME. Similar observations were made in a processing comparison study (KSD and HME) of griseofulvin in varying molecular weight grades of HPMC and PVP (120), where HPMC compositions prepared by extrusion exhibited increased discoloration. This study also demonstrated the ability of KSD to more readily render amorphous dispersions containing higher drug loads and utilizing higher molecular weight grades of PVP (PVP K30 and PVP K90), which could not be processed by HME without a plasticizer. The higher

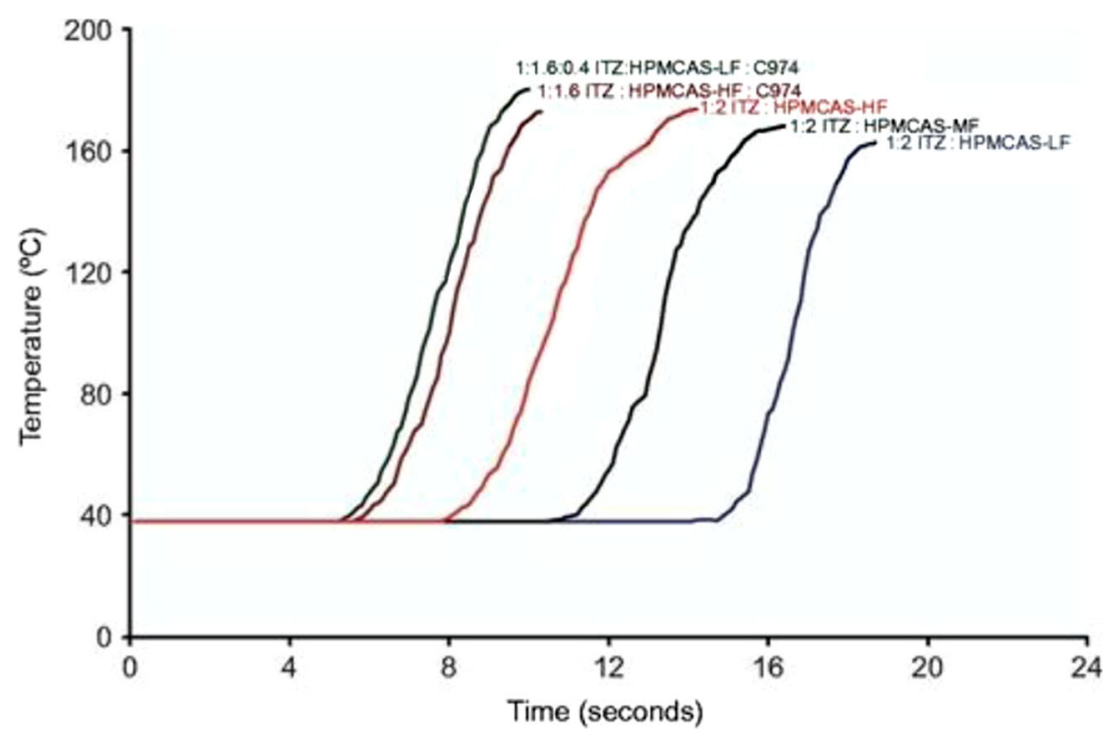

Fig. 5. KinetiSol ${ }^{\circledR}$ processing temperature profiles for manufactured formulations. Reproduced with permission from (118) 
drug loading was attributed to the increased solubilization kinetics from the high shear rates of the KSD process, which enabled production of ASDs at processing temperatures more than $60^{\circ} \mathrm{C}$ below the melting point of griseofulvin.

This increased rate of shear and shorter processing durations is especially effective for processing ASDs containing high melting point and thermally labile APIs (121,122). High melting point APIs can be difficult to render amorphous within the extrusion-processing windows of many pharmaceutical polymers. An example is the investigational drug 3-acetyl-11keto-beta-boswellic acid (AKBA), which has a melting point of $295^{\circ} \mathrm{C}$ and was unable to be processed at target drug loads into an ASD by HME (123). KSD processing, however, was able to render ASDs of AKBA at temperatures as much as $160^{\circ} \mathrm{C}$ below the melting point of the drug, with potencies in excess of $99 \%$. For thermally labile-high melting point compounds, such as meloxicam (MLX), the decreased temperature requirements and shorter duration of KSD was shown to result in greater MLX recovery compared to compositions produced by HME (97). ASDs of MLX and Soluplus ${ }^{\circledR}$ could be processed at temperatures as low as $110^{\circ} \mathrm{C}$ by KSD resulting in a potency of $98.6 \%$, while temperatures of $175^{\circ} \mathrm{C}$ with a 2-min recirculation time was required to render MLX amorphous by HME, resulting in a MLX potency of $87 \%$.

While several promising studies have been published demonstrating the benefits of KSD in producing ASDs and modified release dosage forms, the technology is still nascent and proprietary, with no commercial products to date. However, cGMP manufacturing capabilities do exist and earlyphase clinical trials have commenced utilizing the technology.

\section{CONCLUSION}

Production of ASDs by thermal processing continues to gain interest in the pharmaceutical industry. However, more than $50 \%$ of polymer carriers lack a temperature range (defined by thermal and viscoelastic properties) in which they can be processed by hot-melt extrusion, the most established thermal processing technology. In addition, many polymer carriers have thermal processing temperature ranges that are relatively high, which may exclude processing of thermally labile APIs. Various strategies such as the use of traditional plasticizers, temporary plasticizers, novel application-specific polymers, and alternative thermal processing technologies (e.g., KinetiSol ${ }^{\circledR}$ Dispersing) have all been investigated to enable challenging compositions. The selection of the appropriate strategy depends on a number of factors including the physicochemical attributes of the final product (e.g., physical and chemical stability), the engineering complexity, the availability of new equipment or materials, and how established a process or material is for the pharmaceutical industry.

\section{REFERENCES}

1. Kawabata Y, Wada K, Nakatani M, Yamada S, Onoue S. Formulation design for poorly water-soluble drugs based on biopharmaceutics classification system: basic approaches and practical applications. Int J Pharm. 2011;420(1):1-10. doi:10.1016/j.ijpharm.2011.08.032.

2. Dahan A, Miller JM, Amidon GL. Prediction of solubility and permeability class membership: provisional BCS classification of the world's top oral drugs. AAPS J. 2009;11(4):740-6. doi:10.1208/s12248-009-9144-x.

3. Amidon GL, Lennernas H, Shah VP, Crison JR. A theoretical basis for a biopharmaceutic drug classification: the correlation of in vitro drug product dissolution and in vivo bioavailability. Pharm Res. 1995;12(3):413-20.

4. Williams III RO, Watts AB, Miller DA. Formulating poorly water soluble drugs. Springer Science \& Business Media; 2011

5. Fahr A, Liu X. Drug delivery strategies for poorly water-soluble drugs. Expert Opin Drug Deliv. 2007;4(4):403-16. doi:10.1517/ 17425247.4.4.403.

6. Elder DP, Holm R, de Diego HL. Use of pharmaceutical salts and cocrystals to address the issue of poor solubility. Int J Pharm. 2013;453(1):88-100. doi:10.1016/J.Ijpharm.2012.11.028.

7. Humberstone AJ, Charman WN. Lipid-based vehicles for the oral delivery of poorly water soluble drugs. Adv Drug Delivery Rev. 1997;25(1):103-28. doi:10.1016/S0169-409x(96)00494-2.

8. Challa R, Ahuja A, Ali J, Khar RK. Cyclodextrins in drug delivery: an updated review. AAPS PharmSciTech. 2005;6(2):E329-57. doi:10.1208/pt060243.

9. Chen H, Khemtong C, Yang X, Chang X, Gao J. Nanonization strategies for poorly water-soluble drugs. Drug Discov Today. 2011;16(7-8):354-60. doi:10.1016/j.drudis.2010.02.009.

10. Hu J, Johnston KP, Williams 3rd RO. Nanoparticle engineering processes for enhancing the dissolution rates of poorly water soluble drugs. Drug Dev Ind Pharm. 2004;30(3):233-45. doi:10.1081/DDC-120030422.

11. Janssens S, Van den Mooter G. Review: physical chemistry of solid dispersions. J Pharm Pharmacol. 2009;61(12):1571-86. doi:10.1211/jpp/61.12.0001.

12. Leuner C, Dressman J. Improving drug solubility for oral delivery using solid dispersions. Eur J Pharm Biopharm. 2000;50(1):47-60. doi:10.1016/S0939-6411(00)00076-X.

13. Shah N, Sandhu H, Choi DS, Chokshi H, Malick AW. Amorphous solid dispersions: theory and practice. New York: Springer; 2014

14. Brough C, Williams 3rd RO. Amorphous solid dispersions and nano-crystal technologies for poorly water-soluble drug delivery. Int J Pharm. 2013;453(1):157-66. doi:10.1016/j.ijpharm.2013.05.061.

15. Shah S, Repka MA. Melt extrusion in drug delivery: three decades of progress. Melt extrusion. New York: Springer; 2013. p. 3-46.

16. Hancock BC, Parks M. What is the true solubility advantage for amorphous pharmaceuticals? Pharm Res. 2000;17(4):397-404. doi:10.1023/A:1007516718048.

17. Ueda K, Higashi K, Limwikrant W, Sekine S, Horie T, Yamamoto K, et al. Mechanistic differences in permeation behavior of supersaturated and solubilized solutions of carbamazepine revealed by nuclear magnetic resonance measurements. Mol Pharm. 2012;9(11):3023-33. doi:10.1021/mp300083e.

18. Miller JM, Beig A, Carr RA, Spence JK, Dahan A. A win-win solution in oral delivery of lipophilic drugs: supersaturation via amorphous solid dispersions increases apparent solubility without sacrifice of intestinal membrane permeability. Mol Pharm. 2012;9(7):2009-16. doi:10.1021/mp300104s.

19. Miller JM, Beig A, Carr RA, Webster GK, Dahan A. The solubility-permeability interplay when using cosolvents for solubilization: revising the way we use solubility-enabling formulations. Mol Pharm. 2012;9(3):581-90. doi:10.1021/mp200460u.

20. Miller JM, Beig A, Krieg BJ, Carr RA, Borchardt TB, Amidon GE, et al. The solubility-permeability interplay: mechanistic modeling and predictive application of the impact of micellar solubilization on intestinal permeation. Mol Pharm. 2011;8(5):1848-56. doi:10.1021/mp200181v.

21. Dahan A, Miller JM, Hoffman A, Amidon GE, Amidon GL. The solubility-permeability interplay in using cyclodextrins as pharmaceutical solubilizers: mechanistic modeling and application to progesterone. J Pharm Sci. 2010;99(6):2739-49. doi:10.1002/jps.22033.

22. Padden BE, Miller JM, Robbins T, Prasad L, Spence JK, LaFountaine J. Formulation development-amorphous solid dispersions as enabling formulations for discovery and early development. Am Pharm Rev. 2011;14(1):66.

23. Vasconcelos T, Sarmento B, Costa P. Solid dispersions as strategy to improve oral bioavailability of poor water soluble drugs. 
Drug Discov Today. 2007;12(23-24):1068-75. doi:10.1016/ J.Drudis.2007.09.005.

24. Paudel A, Worku ZA, Meeus J, Guns S, Van den Mooter G. Manufacturing of solid dispersions of poorly water soluble drugs by spray drying: formulation and process considerations. Int $\mathbf{J}$ Pharm. 2013;453(1):253-84. doi:10.1016/j.ijpharm.2012.07.015.

25. Nandiyanto ABD, Okuyama K. Progress in developing spraydrying methods for the production of controlled morphology particles: from the nanometer to submicrometer size ranges. Adv Powder Technol. 2011;22(1):1-19. doi:10.1016/ J.Apt.2010.09.011.

26. Witschi C, Doelker E. Residual solvents in pharmaceutical products: acceptable limits, influences on physicochemical properties, analytical methods and documented values. Eur J Pharm Biopharm. 1997;43(3):215-42. doi:10.1016/S09396411(96)00037-9.

27. Keen JM, McGinity JW, Williams 3rd RO. Enhancing bioavailability through thermal processing. Int J Pharm. 2013;450(12):185-96. doi:10.1016/j.ijpharm.2013.04.042.

28. Vynckier AK, Dierickx L, Voorspoels J, Gonnissen Y, Remon JP, Vervaet C. Hot-melt co-extrusion: requirements, challenges and opportunities for pharmaceutical applications. J Pharm Pharmacol. 2014;66(2):167-79. doi:10.1111/jphp.12091.

29. Lang B, McGinity JW, Williams 3rd RO. Hot-melt extrusion-basic principles and pharmaceutical applications. Drug Dev Ind Pharm. 2014;40(9):1133-55. doi:10.3109/03639045.2013.838577.

30. Repka MA, Battu SK, Upadhye SB, Thumma S, Crowley MM, Zhang F, et al. Pharmaceutical applications of hot-melt extrusion: part II. Drug Dev Ind Pharm. 2007;33(10):1043-57. doi:10.1080/03639040701525627.

31. Crowley MM, Zhang F, Repka MA, Thumma S, Upadhye SB, Battu SK, et al. Pharmaceutical applications of hot-melt extrusion: part I. Drug Dev Ind Pharm. 2007;33(9):909-26. doi:10.1080/03639040701498759.

32. Keen JM, Martin C, Machado A, Sandhu H, McGinity JW, DiNunzio JC. Investigation of process temperature and screw speed on properties of a pharmaceutical solid dispersion using corotating and counter-rotating twin-screw extruders. J Pharm Pharmacol. 2014;66(2):204-17. doi:10.1111/jphp.12106.

33. Breitenbach J. Melt extrusion: from process to drug delivery technology. Eur J Pharm Biopharm Off J Arbeitsgemeinschaft fur Pharmazeutische Verfahrenstechnik eV. 2002;54(2):107-17.

34. Shah SP, Breitenbach J. Melt extrusion: a commercial perception to practicality. Melt extrusion. New York: Springer; 2013. p. 447-58.

35. EMA. Viekirax assessment report. United Kingdom; 2014.

36. Liepold B, Jung T, Peter H, Schroeder R, Sever NE, Lafountaine JS, et al. Solid compositions. In: USPTO, editor. US Patent No 8,686,026. United States: AbbVie, Inc.; 2014.

37. Packhaeuser C, Steiger N, Liepold B, Kostelac D, Knobloch M. Pharmaceutical dosage form for oral administration of a BCL 2 family inhibitor. U.S. Patent Application 12/796,000; 2010.

38. Krishna G, Ma L, Martinho M, Preston RA, O'Mara E. A new solid oral tablet formulation of posaconazole: a randomized clinical trial to investigate rising single- and multiple-dose pharmacokinetics and safety in healthy volunteers. J Antimicrob Chemother. 2012;67(11):2725-30. doi:10.1093/jac/dks268.

39. EMA. Noxafil assessment report. United Kingdom; 2014.

40. Krishna G, Ma L, Martinho M, O'Mara E. Single-dose phase I study to evaluate the pharmacokinetics of posaconazole in new tablet and capsule formulations relative to oral suspension. Antimicrob Agents Chemother. 2012;56(8):4196-201. doi:10.1128/AAC.00222-12.

41. Sarode AL, Sandhu H, Shah N, Malick W, Zia H. Hot melt extrusion (HME) for amorphous solid dispersions: predictive tools for processing and impact of drug-polymer interactions on supersaturation. Eur J Pharm Sci Off J Eur Fed Pharm Sci. 2013;48(3):371-84. doi:10.1016/j.ejps.2012.12.012.

42. Qian F, Huang J, Hussain MA. Drug-polymer solubility and miscibility: stability consideration and practical challenges in amorphous solid dispersion development. J Pharm Sci. 2010;99(7):2941-7. doi:10.1002/jps.22074.

43. Marsac PJ, Shamblin SL, Taylor LS. Theoretical and practical approaches for prediction of drug-polymer miscibility and solubility. Pharm Res. 2006;23(10):2417-26. doi:10.1007/s11095-0069063-9.
44. Kyeremateng SO, Pudlas M, Woehrle GH. A fast and reliable empirical approach for estimating solubility of crystalline drugs in polymers for hot melt extrusion formulations. J Pharm Sci. 2014;103(9):2847-58. doi:10.1002/jps.23941.

45. Kolter K, Karl M, Gryczke A, Ludwigshafen am Rhein B. Hotmelt extrusion with BASF pharma polymers: extrusion compendium. 2nd ed. ed: BASF; 2012.

46. Gupta SS, Meena A, Parikh T, Serajuddin AT. Investigation of thermal and viscoelastic properties of polymers relevant to hot melt extrusion, I: polyvinylpyrrolidone and related polymers. J Excipients Food Chem. 2014;5(1):32-45.

47. Parikh T, Gupta SS, Meena A, Serajuddin AT. Investigation of thermal and viscoelastic properties of polymers relevant to hot melt extrusion, III: polymethacrylates and polymethacrylic acid based polymers. J Excipients Food Chem. 2014;5(1):56-64.

48. Meena A, Parikh T, Gupta SS, Serajuddin AT. Investigation of thermal and viscoelastic properties of polymers relevant to hot melt extrusion, II: cellulosic polymers. J Excipients Food Chem. 2014:5(1):46-55.

49. Rowe RC, Sheskey PJ, Owen SC, American Pharmacists Association., R2 Library (Online service). Handbook of pharmaceutical excipients. In. Pharmaceutical Pres; American Pharmacists Association; 2006. http://www.UTXA.eblib.com/patron/ FullRecord.aspx? $\mathrm{p}=363944$.

50. Matsumoto T, Zografi G. Physical properties of solid molecular dispersions of indomethacin with poly(vinylpyrrolidone) and poly(vinylpyrrolidone-co-vinyl-acetate) in relation to indomethacin crystallization. Pharm Res. 1999;16(11):1722-8.

51. Qiu Y, Chen Y, Zhang GG, Liu L, Porter W. Developing solid oral dosage forms: pharmaceutical theory \& practice. Waltham: Academic; 2009.

52. Klueglich M, Ring A, Scheuerer S, Trommeshauser D, Schuijt $\mathrm{C}$, Liepold $\mathrm{B}$, et al. Ibuprofen extrudate, a novel, rapidly dissolving ibuprofen formulation: relative bioavailability compared to ibuprofen lysinate and regular ibuprofen, and food effect on all formulations. J Clin Pharmacol. 2005;45(9):1055-61. doi:10.1177/0091270005279579.

53. Siepmann J, Peppas NA. Modeling of drug release from delivery systems based on hydroxypropyl methylcellulose (HPMC). Adv Drug Deliv Rev. 2001;48(2-3):139-57.

54. Edgar KJ. Cellulose esters in drug delivery. Cellulose. 2007;14(1):49-64. doi:10.1007/S10570-006-9087-7.

55. Curatolo W, Nightingale JA, Herbig SM. Utility of hydroxypropylmethylcellulose acetate succinate (HPMCAS) for initiation and maintenance of drug supersaturation in the GI milieu. Pharm Res. 2009;26(6):1419-31. doi:10.1007/s11095-009-9852-z.

56. Shah N, Sandhu H, Phuapradit W, Pinal R, Iyer R, Albano A, et al. Development of novel microprecipitated bulk powder (MBP) technology for manufacturing stable amorphous formulations of poorly soluble drugs. Int J Pharm. 2012;438(1-2):5360. doi:10.1016/j.jpharm.2012.08.031.

57. Six K, Berghmans H, Leuner C, Dressman J, Van Werde K, Mullens J, et al. Characterization of solid dispersions of itraconazole and hydroxypropylmethylcellulose prepared by melt extrusion, part II. Pharm Res. 2003;20(7):1047-54.

58. Miller DA, DiNunzio JC, Yang W, McGinity JW, Williams 3rd RO. Targeted intestinal delivery of supersaturated itraconazole for improved oral absorption. Pharm Res. 2008;25(6):1450-9. doi:10.1007/s11095-008-9543-1.

59. Dong Z, Chatterji A, Sandhu H, Choi DS, Chokshi H, Shah N. Evaluation of solid state properties of solid dispersions prepared by hot-melt extrusion and solvent co-precipitation. Int J Pharm. 2008;355(1-2):141-9. doi:10.1016/j.ijpharm.2007.12.017.

60. Ghosh I, Snyder J, Vippagunta R, Alvine M, Vakil R, Tong WQ, et al. Comparison of HPMC based polymers performance as carriers for manufacture of solid dispersions using the melt extruder. Int J Pharm. 2011;419(1-2):12-9. doi:10.1016/ j.ijpharm.2011.05.073.

61. Verreck G, Six K, Van den Mooter G, Baert L, Peeters J, Brewster ME. Characterization of solid dispersions of itraconazole and hydroxypropylmethylcellulose prepared by melt extrusion-part I. Int J Pharm. 2003;251(1-2):165-74.

62. McGinity JW, Zhang F. Melt-extruded controlled-release dosage forms. Drugs Pharm Sci. 2003;133:183-208. 
63. Verreck G. The influence of plasticizers in hot-melt extrusion. Hot-Melt Extrusion: Pharm Appl. 2012:93-112.

64. Schilling SU, Shah NH, Malick AW, Infeld MH, McGinity JW. Citric acid as a solid-state plasticizer for Eudragit RS PO. J Pharm Pharmacol. 2007;59(11):1493-500. doi:10.1211/ jpp.59.11.0005.

65. Wu C, McGinity JW. Influence of methylparaben as a solid-state plasticizer on the physicochemical properties of Eudragit RS PO hot-melt extrudates. Eur J Pharm Biopharm Off J Arbeitsgemeinschaft fur Pharmazeutische Verfahrenstechnik eV. 2003;56(1):95-100.

66. Maru SM, de Matas M, Kelly A, Paradkar A. Characterization of thermal and rheological properties of zidovudine, lamivudine and plasticizer blends with ethyl cellulose to assess their suitability for hot melt extrusion. Eur J Pharm Sci Off J Eur Fed Pharm Sci. 2011;44(4):471-8. doi:10.1016/j.ejps.2011.09.003.

67. Schilling SU, Shah NH, Waseem Malick A, McGinity JW. Properties of melt extruded enteric matrix pellets. Eur J Pharm Biopharm Off J Arbeitsgemeinschaft fur Pharmazeutische Verfahrenstechnik eV. 2010;74(2):352-61. doi:10.1016/ j.ejpb.2009.09.008.

68. Schilling SU, Lirola HL, Shah NH, Waseem Malick A, McGinity JW. Influence of plasticizer type and level on the properties of Eudragit S100 matrix pellets prepared by hot-melt extrusion. J Microencapsul. 2010;27(6):521-32. doi:10.3109/ 02652048.2010.484105.

69. Ghebremeskel AN, Vernavarapu C, Lodaya M. Use of surfactants as plasticizers in preparing solid dispersions of poorly soluble API: selection of polymer-surfactant combinations using solubility parameters and testing the processability. Int J Pharm. 2007;328(2):119-29. doi:10.1016/J.Ijpharm.2006.08.010.

70. Ghebremeskel AN, Vemavarapu C, Lodaya M. Use of surfactants as plasticizers in preparing solid dispersions of poorly soluble API: stability testing of selected solid dispersions. Pharm Res. 2006;23(8):1928-36. doi:10.1007/s11095-006-9034-1.

71. Janssens S, de Armas HN, D'Autry W, Van Schepdael A, Van den Mooter G. Characterization of ternary solid dispersions of itraconazole in polyethylene glycol 6000/polyvidonevinylacetate 64 blends. Eur J Pharm Biopharm Off J Arbeitsgemeinschaft fur Pharmazeutische Verfahrenstechnik eV. 2008;69(3):1114-20. doi:10.1016/j.ejpb.2008.02.007.

72. Janssens S, de Armas HN, Roberts CJ, Van den Mooter G. Characterization of ternary solid dispersions of itraconazole, PEG 6000, and HPMC 2910 E5. J Pharm Sci. 2008;97(6):211020. doi:10.1002/jps.21128.

73. Janssens S, Nagels S, Armas HN, D'Autry W, Van Schepdael A, Van den Mooter G. Formulation and characterization of ternary solid dispersions made up of Itraconazole and two excipients, TPGS 1000 and PVPVA 64, that were selected based on a supersaturation screening study. Eur J Pharm Biopharm Off J Arbeitsgemeinschaft fur Pharmazeutische Verfahrenstechnik eV. 2008;69(1):158-66. doi:10.1016/j.ejpb.2007.11.004.

74. Janssens S, Roberts C, Smith EF, Van den Mooter G. Physical stability of ternary solid dispersions of itraconazole in polyethyleneglycol 6000/hydroxypropylmethylcellulose 2910 E5 blends. Int J Pharm. 2008;355(1-2):100-7. doi:10.1016/ j.ijpharm.2007.11.054.

75. Goddeeris C, Willems T, Van den Mooter G. Formulation of fast disintegrating tablets of ternary solid dispersions consisting of TPGS 1000 and HPMC 2910 or PVPVA 64 to improve the dissolution of the anti-HIV drug UC 781. Eur J Pharm Sci Off J Eur Fed Pharm Sci. 2008;34(4-5):293-302. doi:10.1016/ j.ejps.2008.05.005.

76. Ilevbare GA, Liu H, Edgar KJ, Taylor LS. Effect of binary additive combinations on solution crystal growth of the poorly water-soluble drug, ritonavir. Cryst Growth Des. 2012;12(12):6050-60.

77. Mosquera-Giraldo LI, Trasi NS, Taylor LS. Impact of surfactants on the crystal growth of amorphous celecoxib. Int J Pharm. 2014;461(1-2):251-7. doi:10.1016/j.ijpharm.2013.11.057.

78. Tho I, Liepold B, Rosenberg J, Maegerlein M, Brandl M, Fricker G. Formation of nano/micro-dispersions with improved dissolution properties upon dispersion of ritonavir melt extrudate in aqueous media. Eur J Pharm Sci. 2010;40(1):25-32. doi:10.1016/j.ejps.2010.02.003.
79. Kanzer J, Hupfeld S, Vasskog T, Tho I, Holig P, Magerlein M, et al. In situ formation of nanoparticles upon dispersion of melt extrudate formulations in aqueous medium assessed by asymmetrical flow field-flow fractionation. J Pharm Biomed Anal. 2010;53(3):359-65. doi:10.1016/j.jpba.2010.04.012.

80. Ilevbare GA, Liu H, Pereira J, Edgar KJ, Taylor LS. Influence of additives on the properties of nanodroplets formed in highly supersaturated aqueous solutions of ritonavir. Mol Pharm. 2013;10(9):3392-403. doi:10.1021/mp400228x.

81. DiNunzio JC, Brough C, Miller DA, Williams 3rd RO, McGinity JW. Applications of KinetiSol dispersing for the production of plasticizer free amorphous solid dispersions. Eur J Pharm Sci Off J Eur Fed Pharm Sci. 2010;40(3):179-87. doi:10.1016/ j.ejps.2010.03.002.

82. Sauceau M, Fages J, Common A, Nikitine C, Rodier E. New challenges in polymer foaming: a review of extrusion processes assisted by supercritical carbon dioxide. Prog Polym Sci. 2011;36(6):749-66. doi:10.1016/J.Progpolymsci.2010.12.004.

83. Chiou JS, Barlow JW, Paul DR. Plasticization of glassypolymers by Co2. J Appl Polym Sci. 1985;30(6):2633-42. doi:10.1002/App.1985.070300626.

84. Nalawade SP, Picchioni F, Janssen LPBM. Supercritical carbon dioxide as a green solvent for processing polymer melts: processing aspects and applications. Prog Polym Sci. 2006;31(1):1943. doi:10.1016/J.Progpolymsci.2005.08.002.

85. Martin C. Twin screw extrusion for pharmaceutical processes. Melt extrusion. New York: Springer; 2013. p. 47-79.

86. Verreck G, Decorte A, Li HB, Tomasko D, Arien A, Peeters J, et al. The effect of pressurized carbon dioxide as a plasticizer and foaming agent on the hot melt extrusion process and extrudate properties of pharmaceutical polymers. J Supercrit Fluid. 2006;38(3):383-91. doi:10.1016/J.Supflu.2005.11.022.

87. Lyons JG, Hallinan M, Kennedy JE, Devine DM, Geever LM, Blackie $\mathrm{P}$, et al. Preparation of monolithic matrices for oral drug delivery using a supercritical fluid assisted hot melt extrusion process. Int J Pharm. 2007;329(1-2):62-71. doi:10.1016/ J.Ijpharm.2006.08.028.

88. Kiran E. Polymer formation, modifications and processing in or with supercritical fluids. Supercritical fluids. Springer; 1994. p. 541-88.

89. Nikitine C, Rodier E, Sauceau M, Letourneau JJ, Fages J. Controlling the structure of a porous polymer by coupling supercritical $\mathrm{CO} 2$ and single screw extrusion process. J Appl Polym Sci. 2010;115(2):981-90. doi:10.1002/App.31031.

90. Verreck G, Decorte A, Heymans K, Adriaensen J, Liu DH, Tomasko DL, et al. The effect of supercritical $\mathrm{CO}(2)$ as a reversible plasticizer and foaming agent on the hot stage extrusion of itraconazole with EC $20 \mathrm{cps}$. J Supercrit Fluid. 2007;40(1):153-62. doi:10.1016/J.Supflu.2006.05.005.

91. Verreck G, Decorte A, Heymans K, Adriaensen J, Cleeren D, Jacobs A, et al. The effect of pressurized carbon dioxide as a temporary plasticizer and foaming agent on the hot stage extrusion process and extrudate properties of solid dispersions of itraconazole with PVP-VA 64. Eur J Pharm Sci Off J Eur Fed Pharm Sci. 2005;26(3-4):349-58. doi:10.1016/ j.ejps.2005.07.006.

92. Verreck G, Decorte A, Heymans K, Adriaensen J, Liu D, Tomasko $\mathrm{D}$, et al. Hot stage extrusion of p-amino salicylic acid with EC using $\mathrm{CO} 2$ as a temporary plasticizer. Int $\mathrm{J}$ Pharm. 2006;327(1-2):45-50. doi:10.1016/J.Ijpharm.2006.07.024.

93. Ashour EA, Kulkarni V, Almutairy B, Park JB, Shah SP, Majumdar S, et al. Influence of pressurized carbon dioxide on ketoprofen-incorporated hot-melt extruded low molecular weight hydroxypropylcellulose. Drug Dev Ind Pharm. 2015:18. doi: 10.3109/03639045.2015.1035282.

94. Reintjes T. Solubility enhancement with BASF pharma polymers-solubilizer compendium. BASF (Ed). 2011:67-8.

95. Djuris J, Nikolakakis I, Ibric S, Djuric Z, Kachrimanis K. Preparation of carbamazepine-Soluplus solid dispersions by hot-melt extrusion, and prediction of drug-polymer miscibility by thermodynamic model fitting. Eur J Pharm Biopharm Off J Arbeitsgemeinschaft fur Pharmazeutische Verfahrenstechnik eV. 2013;84(1):228-37. doi:10.1016/j.ejpb.2012.12.018.

96. Gupta SS, Parikh T, Meena AK, Mahajan N, Vitez I, Serajuddin AT. Effect of carbamazepine on viscoelastic properties and hot 
melt extrudability of Soluplus. Int J Pharm. 2014;478(1):232-9. doi:10.1016/j.ijpharm.2014.11.025.

97. Hughey JR, Keen JM, Brough C, Saeger S, McGinity JW. Thermal processing of a poorly water-soluble drug substance exhibiting a high melting point: the utility of KinetiSol(R) Dispersing. Int $\mathrm{J}$ Pharm. 2011;419(1-2):222-30. doi:10.1016/j.ijpharm.2011.08.007.

98. Alshahrani SM, Lu W, Park JB, Morott JT, Alsulays BB, Majumdar S, et al. Stability-enhanced hot-melt extruded amorphous solid dispersions via combinations of Soluplus(R) and HPMCAS-HF. AAPS PharmSciTech. 2015. doi:10.1208/ s12249-014-0269-6.

99. Dierickx L, Van Snick B, Monteyne T, De Beer T, Remon JP, Vervaet C. Co-extruded solid solutions as immediate release fixed-dose combinations. Eur J Pharm Biopharm Off J Arbeitsgemeinschaft fur Pharmazeutische Verfahrenstechnik eV. 2014;88(2):502-9. doi:10.1016/j.ejpb.2014.06.010.

100. Zhang Y, Liu Y, Luo Y, Yao Q, Zhong Y, Tian B, et al. Extruded Soluplus/SIM as an oral delivery system: characterization, interactions, in vitro and in vivo evaluations. Drug Deliv. 2014:1-10. doi: 10.3109/10717544.2014.960982.

101. Han SD, Jung SW, Jang SW, Jung HJ, Son M, Kim BM, et al. Preparation of solid dispersion of dronedarone hydrochloride with Soluplus $((\mathrm{R}))$ by hot melt extrusion technique for enhanced drug release. Chem Pharm Bull. 2015;63(4):295-9. doi:10.1248/cpb.c14-00725.

102. Lee JY, Kang WS, Piao J, Yoon IS, Kim DD, Cho HJ. Soluplus/ TPGS-based solid dispersions prepared by hot-melt extrusion equipped with twin-screw systems for enhancing oral bioavailability of valsartan. Drug Des Devel Ther. 2015;9:2745-56. doi:10.2147/DDDT.S84070.

103. Coppens K, Hall M, Larsen P, Mitchell S, Nguyen P, Read M, et al., editors. Thermal and rheological evaluation of pharmaceutical excipients for hot melt extrusion. AAPS Annual Meeting and Exposition, Baltimore, MD; 2004.

104. O'Donnell K, Grasman N, Shrestha U, Vanchura B, editors. The utility of AFFINISOL ${ }^{\mathrm{TM}}$ HPMC in hot melt extrusion for supersaturation and controlled release of poorly soluble drugs. AAPS Annual Meeting; San Antonio, TX; 2013.

105. O'Donnell KP, Woodward WH. Dielectric spectroscopy for the determination of the glass transition temperature of pharmaceutical solid dispersions. Drug Dev Ind Pharm. 2015;41(6):959-68. doi:10.3109/03639045.2014.919314.

106. Faham A, editor. Tailoring of cellulose ether excipients to solve oral and nasal delivery challenges. Global drug delivery and formulation summit. Berlin, Germany; 2014.

107. O'Donnell K, Shrestha U, editors. Process and product robustness of solid dispersions of AFFINISOL ${ }^{\mathrm{TM}}$ HPMC HME with BCS class I and class II APIs prepared by hot melt extrusion. AAPS Annual Meeting; San Diego, CA; 2014.

108. Huang S, O'Donnell K, Keen J, McGinity J, Williams R, editors. Evaluation of an extrudable form of hypromellose-AFFINISOLTM HPMC HME. AAPS Annual Meeting; San Diego, CA; 2014.

109. Thiry J, Evrard B, editors. Preformulation study of an itraconazole-based oral dosage produced by hot-melt extrusion. AAPS Annual Meeting San Diego 2014; 2014.

110. Ueda K, Higashi K, Yamamoto K, Moribe K. Inhibitory effect of hydroxypropyl methylcellulose acetate succinate on drug recrystallization from a supersaturated solution assessed using nuclear magnetic resonance measurements. Mol Pharm. 2013;10(10):3801-11. doi:10.1021/mp400278j.

111. Warashina S, Maruyama N, Quadir A, Obara S, editors. Evaluation of a new development grade of hypromellose acetate succinate (HPMCAS) for solid dispersion by hot melt extrusion. AAPS Annual Meeting; San Diego, CA; 2014.

112. Sarode AL, Obara S, Tanno FK, Sandhu H, Iyer R, Shah N. Stability assessment of hypromellose acetate succinate (HPMCAS) NF for application in hot melt extrusion (HME). Carbohydr Polym. 2014;101:146-53. doi:10.1016/ j.carbpol.2013.09.017.

113. Zong Y, Brugel T, Chen T, Hood C, Tewari D, Durig T, editors. New HPMCAS grades with improved solubilization ability and hot-melt extrudability. AAPS Annual Meeting; San Antonio, TX; 2013.

114. Miller DA, Keen JM. KinetiSol@-based amorphous solid dispersions. Amorphous solid dispersions. Springer; 2014. p. 56777.

115. Frenken S, Lyons D, Baker W, editors. Slow motion filming and predictive modelling of a Gelimat K-Mixer. SPE ANTEC Proceedings; 1991.

116. Lyons D, Baker WE. Dynamics of a high-speed melter mixer. Int Polym Process. 1990;5(2):136-41.

117. Gopakumar TG, Page DJYS. Polypropylene/graphite nanocomposites by thermo-kinetic mixing. Polym Eng Sci. 2004;44(6):1162-9. doi:10.1002/Pen.20109.

118. DiNunzio JC, Hughey JR, Brough C, Miller DA, Williams 3rd RO, McGinity JW. Production of advanced solid dispersions for enhanced bioavailability of itraconazole using KinetiSol dispersing. Drug Dev Ind Pharm. 2010;36(9):1064-78. doi:10.3109/ 03639041003652973.

119. Hughey JR, Keen JM, Miller DA, Brough C, McGinity JW. Preparation and characterization of fusion processed solid dispersions containing a viscous thermally labile polymeric carrier. Int J Pharm. 2012;438(1-2):11-9. doi:10.1016/ j.ijpharm.2012.08.032.

120. LaFountaine JS, Prasad LK, Brough C, Ford K, Williams III $\mathrm{RO}$, McGinity J, editors. Processing and characterization of PVP- and HPMC-based amorphous solid dispersions: a comparison of hot melt extrusion and KinetiSol® Dispersing. AAPS Annual Meeting; San Diego, CA; 2014.

121. Hughey JR, DiNunzio JC, Bennett RC, Brough C, Miller DA, Ma $\mathrm{H}$, et al. Dissolution enhancement of a drug exhibiting thermal and acidic decomposition characteristics by fusion processing: a comparative study of hot melt extrusion and KinetiSol dispersing. AAPS PharmSciTech. 2010;11(2):760-74. doi:10.1208/s12249-010-9431-y.

122. Dinunzio JC, Brough C, Hughey JR, Miller DA, Williams 3rd RO, McGinity JW. Fusion production of solid dispersions containing a heat-sensitive active ingredient by hot melt extrusion and Kinetisol dispersing. Eur J Pharm Biopharm Off J Arbeitsgemeinschaft fur Pharmazeutische Verfahrenstechnik eV. 2010;74(2):340-51. doi:10.1016/j.ejpb.2009.09.007.

123. Bennett RC, Brough C, Miller DA, O'Donnell KP, Keen JM, Hughey JR, et al. Preparation of amorphous solid dispersions by rotary evaporation and KinetiSol dispersing: approaches to enhance solubility of a poorly water-soluble gum extract. Drug Dev Ind Pharm. 2015;41(3):382-97. doi:10.3109/ 03639045.2013.866142. 